\title{
Minireview \\ Intragenic DNA methylation: implications of this epigenetic mechanism for cancer research
}

\author{
N Shenker' and JM Flanagan*, \\ 'Epigenetics Unit, Department of Surgery and Cancer, Hammersmith Hospital, Faculty of Medicine, Imperial College London, 4th Floor IRDB, \\ Hammersmith Campus, Du Cane Road, London WI 2 ONN, UK
}

Epigenetics is the study of all mechanisms that regulate gene transcription and genome stability that are maintained throughout the cell division, but do not include the DNA sequence itself. The best-studied epigenetic mechanism to date is DNA methylation, where methyl groups are added to the cytosine base within cytosine-guanine dinucleotides (CpG sites). CpGs are frequently clustered in high density (CpG islands (CGls)) at the promoter of over half of all genes. Current knowledge of transcriptional regulation by DNA methylation centres on its role at the promoter where unmethylated CGls are present at most actively transcribed genes, whereas hypermethylation of the promoter results in gene repression. Over the last 5 years, research has gradually incorporated a broader understanding that methylation patterns across the gene (so-called intragenic or gene body methylation) may have a role in transcriptional regulation and efficiency. Numerous genome-wide DNA methylation profiling studies now support this notion, although whether DNA methylation patterns are a cause or consequence of other regulatory mechanisms is not yet clear. This review will examine the evidence for the function of intragenic methylation in gene transcription, and discuss the significance of this in carcinogenesis and for the future use of therapies targeted against DNA methylation.

British Journal of Cancer (2012) I 06, 248-253. doi:I0.1038/bjc.2011.550 www.bjcancer.com

Published online 13 December 2011

(c) 2012 Cancer Research UK

Keywords: epigenetics; DNA methylation; breast cancer; intragenic; gene-body

One of the principal epigenetic mechanisms that governs the transcriptional regulation of genes is the methylation of $\mathrm{CpG}$ dinucleotides. DNA methylation at the promoter regions is known to be important in both development and human disease, including cancer. $\mathrm{CpG}$ sites tend to cluster in higher densities at promoter regions than throughout the rest of the genome, which has led to the definition of the term, CpG island (CGI; Bird, 1986). These promoter-associated CGIs tend to be unmethylated (Takai and Jones, 2002), whereas up to $80 \%$ of the total number of $\mathrm{CpG}$ sites in a genome are methylated. Furthermore, CpG sites are also found at significantly higher densities in gene-rich compared with gene-poor areas of the human chromosomes (Weber et al, 2005). DNA methylation at promoter $\mathrm{CpG}$ sites leads to the repression of gene expression by altering the conformation of DNA itself and local histone structures (Ng and Bird, 1999; Cedar and Bergman, 2009). Dogma states that this prevents the recruitment of the transcription complex scaffolding that can activate RNA polymerase II. However, this mechanism has only been thought to account for the transcriptional control in approximately half of all genes, and this figure may indeed be as low as a subset of 200 genes in any given cell type (Weber et al, 2005). It is possible that other unexplored functions of DNA methylation have additional roles in the transcriptional process of genes that do not contain a promoter-associated CGI.

*Correspondence: Dr JM Flanagan; E-mail: j.flanagan@imperial.ac.uk Received 16 July 2011; revised 14 November 2011; accepted 24 November 201 I; published online 13 December 201 I
In cancers, a substantial proportion of genes with promoterassociated CGIs become hypermethylated (Jones and Baylin, 2007). Promoter hypermethylation frequently silences tumour-suppressor genes in cancers. Indeed, profiling of specific sites or panels of sites that are aberrantly methylated within tumour cells are currently being investigated as biomarkers of early prediction and prognostication, where cancer-associated methylation can be detected in tumour biopsy samples, cell-free serum, urine and peritoneal fluid (Schulz and Goering, 2011). Furthermore, DNA methylation profiling can also be used to define novel tumour subgroups (Flanagan, 2011).

A further understanding of the epigenetic mechanisms that regulate gene transcription in pathological states such as cancer will be crucial in the development of novel and innovative therapies for these diseases. Already, promoter hypermethylation can be reversed by non-specific demethylating agents, such as decitabine and 5-azacytidine (5-aza), which have been approved in the therapy of several haematological malignancies (Fandy et al, 2007). Few clinical trials of demethylating agents in solid tumours have been performed. To date, the largest phase 1 study in solid tumours suggested that the doses required to produce the same effects in humans as in mice were tolerable (Appleton et al, 2007), but as yet solid tumour demethylating therapies have not been successful in humans. The first published phase $2 \mathrm{a}$ trial suggested that azacytidine could help to reverse the platinum-based drug resistance in the patients with ovarian cancer (Fu et al, 2011). Although the intention of demethylating agents is to reactivate promoters that are silenced by promoter hypermethylation, the entire genome could become demethylated, including intragenic 
sequences. Recent investigations have also suggested that 5-aza has broader effects than purely as a demethylating agent, including altering activating histone modifications to repressive marks, and expression changes independent of promoter methylation (Komashko et al, 2008). However, this study only examined promoter regions and further insights may be gained by investigating the intragenic effects of demethylating agents on both histone and DNA methylation. The temporal nature of these events also requires further investigation. Therefore, understanding the role of intragenic methylation (IGM) in transcription and in carcinogenesis is critical to understand the full consequences of chemically induced demethylation as a therapy.

\section{IGM IN LOWER ORGANISMS}

Clues regarding the role of IGM in a variety of organisms emerged over a decade ago (Yoder et al, 1997). The basic patterns of IGM are widely conserved throughout the plant and animal kingdoms (Feng et al, 2010; Zemach et al, 2010). In 2006, the first highresolution genome-wide analysis of the methylation of $\mathrm{CpG}$ sites in Arabidopsis thaliana revealed that over one third of the genes had high levels of IGM, but only $5 \%$ of genes had high promoter region methylation (Zhang et al, 2006). A year later, Zilberman et al (2007) established a correlation between DNA methylation and the rate of gene transcription across the whole genome of Arabidopsis. Genes in the plant that were expressed at higher levels (in the top three deciles) tended to have higher levels of IGM than genes expressed at low levels, and all genes had low levels of methylation in the flanking regions (Figure 1). They hypothesised that the role of DNA methylation of the gene body was to suppress the unwanted expression of non-coding RNAs (ncRNAs) and the expression of transposons, which are epigenetically silenced in plants to reduce genomic instability. Frequently expressed genes would have higher levels of IGM in order to reduce the chance of aberrant ncRNAs being expressed or alternative intragenic promoters being active, in comparison with the genes that are expressed less frequently. The length of the gene was also important; shorter genes with higher levels of IGM levels are less likely to be expressed, whereas IGM appeared to have fewer transcriptional effects in longer genes. This may be principally because the effect of methylation on transcription is greatest at the extreme $5^{\prime}$ and $3^{\prime}$ ends of the gene.

\section{THE ROLE OF IGM IN HUMANS}

Several reports have now demonstrated a similar link in humans between the patterns of IGM and expression to those shown in lower organisms (Hellman and Chess, 2007; Ball et al, 2009; Rauch

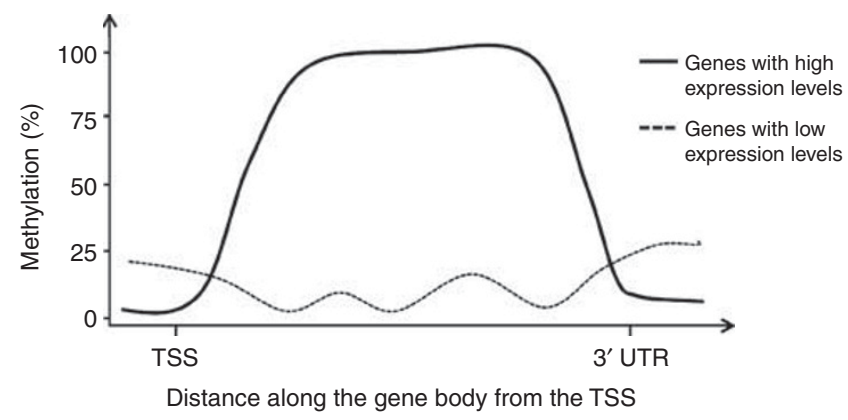

Figure I A schematic of the correlation determined by Zilberman et al for the methylation levels of differentially expressed genes. Abbreviations: TSS, transcription start site; $3^{\prime}$ UTR, three-prime untranslated region. et al, 2009; Aran et al, 2011). In 2007, Hellman and Chess used an array approach to show the pattern of methylation across the $\mathrm{X}$ chromosome to investigate $\mathrm{X}$-linked gene silencing. Contrary to their expectations, the active $\mathrm{X}$ allele was found to have higher levels of methylation than the silenced X allele, and $49 \%$ of the array probes were in intragenic coding regions of known genes. Furthermore, there was no bias towards methylation of repetitive elements in genes, which would have supported the hypothesis that the role of IGM is to suppress repetitive element transcription. Rauch et al (2009) used an enrichment technique for genome-wide methylated DNA to map methylation across the genome of human $B$ cells. They confirmed that methylated intragenic regions correlated with higher levels of gene transcription, and IGM may be a mechanism that regulated the use of alternative promoters. This hypothesis gained supportive evidence from a study that examined DNA methylation in a specific genomic region in the human brain tissues, (Maunakea et al, 2010), discussed later in this review.

A further genome-wide study conducted in different human tissues showed a correlation between the rate of cell division between actively expressed and inactive genes and IGM (Aran $e t a l$, 2011), which mirrored the pattern previously found by Zilberman et al (2007). Furthermore, active and inactive genes in dormant tissue types, such as the brain and lung, were found to have unmethylated promoters and highly methylated intragenic regions, whereas methylation levels were reduced in inactive genes in rapidly dividing tissues such as the placenta and lymphocytes.

The precise definition of a promoter region is being redefined by new evidence that demonstrates the methylated state of the distal promoter region, and indeed extensions into the gene body, is relevant to the expression state of the gene. Appanah et al (2007) showed that the $3^{\prime}$ region of gene promoters had to be unmethylated to enable efficient transcriptional elongation. Recently, Hodges et al (2011) demonstrated hypomethylated regions (HMRs) that extended into the shore regions around promoters, as well as intragenic HMRs. Although the functions of these HMRs are unknown, the intragenic regions are associated with transcription factor binding sites, which suggest a biologically significant role.

The genomes of cancer cells also tend to show global hypomethylation alongside hypermethylation of the gene promoters. The latter has deleterious effects due to the silencing of tumour-suppressor genes and consequent acceleration in the oncogenic process. The causal mechanisms for genomic hypomethylation are still unknown, but a recent analysis suggests that it is unlikely to be due to a dysregulation in DNA repair mechanisms or members of the DNA methyltransferase (DNMT) enzyme family (Wild and Flanagan, 2010). The consequences of hypomethylation, whether intergenic or intragenic, are also unclear, but may act in a similar manner to that postulated in plant intragenic sequences, where demethylation leads to the reactivation of repressed repetitive elements, and potentially further genomic instability. Specific IGM sites have already been implicated in several human cancers. Salem et al studied a panel of cells from human bladder and colon cancers, and found a 550-bp-long HMR of the intragenic region of the PAX6 gene, which mapped to exon 5. PAX6 is a highly conserved protein, which is important during embryogenesis and acts to stimulate uncontrolled cell growth. With the use of transfection studies, they showed that hypermethylation of exon 5 did not impede gene expression, but PAX6 protein levels fell when the promoter region was hypermethylated. In 2007, Smith et al (2007) identified aberrantly methylated areas within non-promoter CGI sites in the genes associated with colonic carcinoma, which appear to have a functional role by affecting mRNA transcription. These few studies have shown the value of investigating regions of DNA methylation in the areas outside of CGIs.

Data on the role and pattern of IGM in specific cancer types are currently limited. In breast cancer, which is the focus of our 
group's work, the distribution of hypomethylated CpG sites in primary tumours and cell lines has been shown to be clustered in gene-poor chromosomal regions, at the $5^{\prime}$ region of frequently expressed genes (including the promoter, first exon and first intron), and large intragenic regions of hypomethylation at chromosomal breakpoints, large genes and tissue-specific gene clusters (Shann et al, 2008). Further work that compares these data with normal tissue samples is required to determine the significance of this finding in cancer cells. We have previously shown significant variability in peripheral blood DNA methylation in the intragenic gene sequences in bilateral breast cancer cases compared with matched healthy control individuals using a tiled microarray (Flanagan et al, 2009). Most of the variability was found in intragenic repetitive elements, and one repetitive element in the ATM gene was associated with a three-fold increased risk of breast cancer in a larger case-control study. These data show potential biomarkers exist in the intragenic sequences of genes.

The first genome-wide sequencing study of a bisulphiteconverted DNA sample from circulating white blood cells of a single individual was recently published ( $\mathrm{Li}$ et al, 2010). These data, which is publically available, enable the genome-wide DNA methylation analysis of candidate genes of interest. Of particular interest in breast cancer is the ESR1 gene, which encodes the oestrogen receptor alpha protein, which we have used to illustrate intragenic DNA methylation from whole-genome bisulphite sequencing data. The expression of ESR 1 is of significant biological and prognostic importance in breast cancer, and largely drives the determination of the management plan. ESR1-positive tumours have broadly better outcomes, with slower-growing tumours on the whole, fewer metastases, and a greater range of hormonally targeted treatment options including tamoxifen and the aromatase inhibitors. Methylation data of the ESR1 gene shows the typical pattern of methylation, with an unmethylated promoter and a highly methylated intragenic region (Figure 2A). Genome-wide bisulphite sequencing data have now been published for embryonic stem cells ( $\mathrm{H} 1$ and hESCs), fibroblast cell lines (IMR90, fibroblasts) and ESCs induced to differentiate into fibroblasts (hESC-fibroblasts; GEO records: GSE19418 and GSE16256 (Figure 2B); http://www.ncbi.nlm.nih.gov/geo/). Information from further cell types will soon become available through projects such as the NIH Epigenomics Roadmap Project (http:// www.roadmapepigenomics.org/). Further work is ongoing in our laboratory to discern the significance of the molecular mechanisms that underlie this pattern and its correlation with expression, and whether specific CpG sites across the ESR1 gene may act as biomarkers. Although there are numerous ongoing studies for predictive and diagnostic biomarker CpG sites in the promoter region, the potential goldmine of information in intragenic regions has been relatively ignored to date.

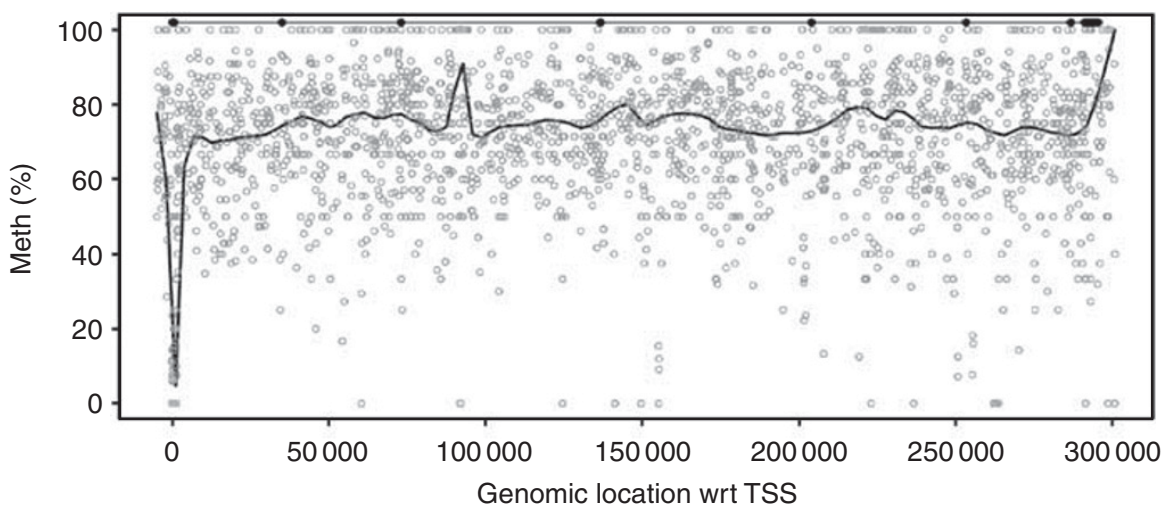

B

ESR1 methylation

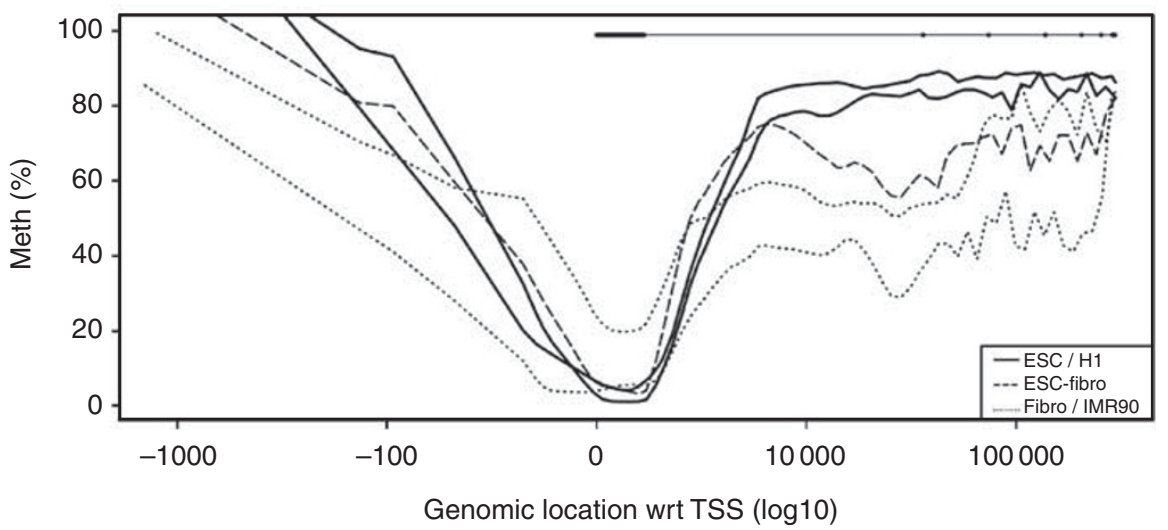

Figure 2 (A) Methylation levels of each CpG site (grey circles) along the full length of the ESR I gene from the transcription start site (indicated by '0' on the $x$ axis). The exons are shown along the uppermost horizontal line as full black circles. The black line indicates the smoothed average methylation levels across the gene. The data were obtained from the bisulphite sequencing study of peripheral mononuclear cells by Li et al (20I0). (B) Genome-wide studies of human embryonic stem cells (ESCs, solid) and lung-derived fibroblasts (dotted) showed different patterns of IGM in the ESR I gene, and a broadly unmethylated promoter region. In ESCs that had differentiated into fibroblasts (dashed), the pattern of IGM bore a greater similarity to the adult differentiated pattern (IMR90 cell line, adult fibroblasts) than wild-type ESCs. The exons are shown along the uppermost horizontal line as full black circles, with $x$ axis showing the log scale genomic location. 


\section{POSTULATED FUNCTIONS OF INTRAGENIC DNA METHYLATION: CAUSE OR CONSEQUENCE?}

Given the conservation of methylation patterns across genes in both plants and animals (Suzuki and Bird, 2008; Feng et al, 2010), it is likely that gene-related DNA methylation is an ancient product of evolution that occurred before these kingdoms diverged, which is evidence of an important function. Early studies recognised the increased level of $\mathrm{CpG}$ in transposons, and postulated that the primary role of the methylation of repetitive elements was to suppress the expression of these parasitic insertions (Yoder et al, 1997). However, other mechanisms have now been proposed.

Intragenic $\mathrm{CpG}$ methylation may act to repress the initiation of transcription from alternative transcription start sites. Maunakea et al (2010) generated a CpG 'map', which included $\sim 88 \%$ of the genomic CpG sites, and then assessed the locations of methylated CpG sites in tissue from human brain tissue. $\mathrm{CpG}$ sites in intragenic, intergenic and promoter regions were found to overlap with sites of transcriptional initiation. The differential methylation levels of these three regions was postulated to correlate with the transcription of alternative isoforms in different tissue types, depending on the transcription start site that was unmethylated. However, the authors acknowledge that this genome-wide approach to the data analysis may prevent the recognition of smaller-scale regulatory mechanisms of DNA methylation. A similar mechanism that has been proposed relates to the modification of the transcriptional efficiency of RNA polymerase II and the transcriptional complex (Lorincz et al, 2004). This could be mediated by the modulation of the regional chromatin structure and may explain why there is a differential pattern of methylation in actively dividing tissues $v s$ dormant tissues.

An alternative hypothesis is that methylation of the DNA along the sense strand could suppress the expression of antisense strand mRNA, either as full-length ncRNA transcripts or microRNAs, being initiated from a variety of intragenic sites. These antisense strands might interfere with the transcription of sense RNA due to their complementarity (Tufarelli et al, 2003), whereby higher levels of antisense copies lead to binding between the sense and antisense strands, reducing the amount of free sense mRNA and consequently reducing the protein translation, in a similar manner to microRNA-mediated gene regulation.

Any hypothesis that accounts for the effects of DNA methylation must take into account the effect of nucleosomes, the constituents of chromatin that package DNA. Nucleosomes consist of an octomer of four histone types (H2A, H2B, H3 and H4), which is wrapped around by a 147-bp DNA. Histone variants have variable affinities for different DNA sequence motifs, including methylated DNA (Segal and Widom, 2009). Histone modifications act locally to either repress or enable transcription. Such modifications include the methylation, acetylation and sumoylation of aminoacid residues on histone tails that extend out from the protein core. CpG density has been found to correlate with specific histone marks, which may have importance in the efficiency of the transcription complex across the gene (Lorincz et al, 2004; Lieb and Clarke, 2005).

The interaction between histone modifications and the intragenic DNA methylation, whether cause or consequence, is still unclear and currently being investigated. For example, the $\mathrm{H} 3 \mathrm{~K} 36 \mathrm{me} 3$ histone mark is enriched at the regions of high CpG density (Hahn et al, 2011). H3K36me3 has been associated with hypermethylated DNA in the intragenic regions of actively expressed genes, where this mark may act to recruit DNMTs and maintain the methylated state (Hawkins et al, 2010). Intragenic H3K36 methylation has been shown in yeast to inhibit gene transcription from alternative start sites (Carrozza et al, 2005). There is some evidence of specific types of histones at exonic regions compared with intronic (Lieb and Clarke, 2005; Huff et al, 2010), including the H3K36me3 mark at the exons of highly expressed genes (Choi, 2010). Interestingly, Hahn et al (2011) indicated that the changes in intragenic DNA methylation levels did not affect the H3K36 histone modification locally and that the alternative reduction of H3K36 methylation by siRNA knockdown of SETD2 did not alter the intragenic DNA methylation. These data support the hypotheses that DNA methylation either occurs as a consequence of the chromatin environment only in some genes, or that two redundant and independent systems of gene repression have evolved. However, these data do not yet provide an answer to the question of cause or consequence, particularly at an individual gene level.

Certain types of histone modifications are associated with aberrant patterns of DNA methylation in cancer. Tri-methylated $\mathrm{H} 3 \mathrm{~K} 9$ (H3K9me3) and $\mathrm{H} 3 \mathrm{~K} 27 \mathrm{me} 3$ are repressive histone modifications. $\mathrm{H} 3 \mathrm{~K} 9 \mathrm{me} 3$ at the promoter region is associated with gene repression in plants, fungi and mammals, although the most recent evidence suggests that it does not affect the efficiency of transcription (Blahnik et al, 2011). The polycomb-associated repressive mark, $\mathrm{H} 3 \mathrm{~K} 27 \mathrm{me}$, is found at aberrantly hypermethylated promoters in both cancer cell lines and tumour samples, where it appears to be preceded by an aberrant DNA methylation signature in inflamed tissues (Hahn et al, 2008). It may be that a form of epigenetic switching occurs at promoters to repress the gene transcription permanently, as DNA methylation replaces the more easily modifiable histone marks (Gal-Yam et al, 2008), but their interactions with DNA methylation across the gene body remain largely unexplored. Indeed, many of the commonly studied histone modifications at promoter regions, such as the activating mark, $\mathrm{H} 3 \mathrm{~K} 4 \mathrm{me} 3$ that prevents DNA methylation at the promoter, have not been studied in depth across the gene body in tumour cells, although numerous studies have shown their relationship with the gene body in normal fetal and adult cell types (Guenther et al, 2007). As yet we can only speculate on the nature of the full interactions between histone modifications and DNA methylation in neoplastic states.

Nucleosome composition at the $5^{\prime}$ region of the gene, within the intragenic region, is of great importance in determining whether the gene is transcribed (reviewed in Lieb and Clarke (2005)). Typical patterns of methylation exist, such as the one shown in Figure 2, which demonstrate a steep increase in methylation levels within the first $8 \mathrm{~kb}$ from the transcription start site in actively expressed genes (Zilberman et al, 2007; Aran et al, 2011). Such patterns suggest that the first few nucleosomes in genes may be highly important for transcriptional efficiency. How this is affected by gene length and transcriptional activity remains unclear, but the recent publication by Han et al (2011) describes an exciting new strategy for the investigation of the temporal sequence of nucleosome occupancy, termed Nucleosome Occupancy Methylome Sequencing (NOME-Seq; Komashko and Farnham, 2010; Nanty et al, 2011). DNA methylation at the loci studied with NOME-Seq appears to occur after nucleosome positioning, and may be influenced by transcription factors, polycomb proteins and other chromatin remodelling factors. Choi et al (2009) also illustrated different levels of nucleosome occupancy and CpG density at the start and end of each exon in the majority of proteincoding genes, which may regulate the pausing of RNA polymerase II at these sites as it traverses the gene.

A recent study demonstrated a link between replication timing and IGM levels, where early replicating genes tended to be active and had higher levels of IGM (Aran et al, 2011). This study also showed a correlation between the rate of cell division between actively expressed and inactive genes, and IGM, which mirrored that pattern previously found by Zilberman et al (2007). Furthermore, active and inactive genes in dormant tissue types, such as the brain and lung, were found to have unmethylated promoters and highly methylated intragenic regions, whereas methylation levels were reduced in inactive genes in rapidly dividing tissues such as the placenta and lymphocytes. This 
preliminary data indicate a link between levels of intragenic DNA methylation and cell proliferation, but does not directly relate to the causality of increased proliferation in cancer cells.

In summary, there are several alternative hypotheses for the association between intragenic DNA methylation and transcription, including modifying transcription efficiency, altering the local histone conformation and producing different levels of sense and antisense mRNA. There is currently more data to support the hypothesis that intragenic DNA methylation is a consequence of other mechanisms of transcriptional regulation, including histone modifications, nucleosome positioning and replication timing. Nevertheless, DNA methylation remains an important marker of intragenic transcriptional efficiency and is experimentally easier to study. Interestingly, recent evidence suggested that variable methylation levels of individual CpG sites affect the binding affinity of transcription factors to nearby binding sites (Flower et al, 2010; Rishi et al, 2010). This may offer a further mechanism by which specific intragenic $\mathrm{CPG}$ sites can affect transcription.

\section{FUTURE PERSPECTIVES}

Most of the work has focussed on CGI-associated methylation, as it is relatively easy to target short regions of DNA for investigation, such as promoter regions. Furthermore, the complexity and the cost of genome-wide, or even chromosomal-wide, studies of epigenetic mechanisms have been prohibitive until recently. With improvements in next generation whole genome bisulphite sequencing, including reduced costs and increased analysis speeds,

\section{REFERENCES}

Appanah R, Dickerson DR, Goyal P, Groudine M, Lorincz MC (2007) An unmethylated $3^{\prime}$ promoter-proximal region is required for efficient transcription initiation. PLoS Genet 3(2): e27

Appleton K, Mackay HJ, Judson I, Plumb JA, McCormick C, Strathdee G, Lee C, Barrett S, Reade S, Jadayel D, Tang A, Bellenger K, Mackay L, Setanoians A, Schatzlein A, Twelves C, Kaye SB, Brown R (2007) Phase I and pharmacodynamic trial of the DNA methyltransferase inhibitor decitabine and carboplatin in solid tumors. J Clin Oncol 25(29): $4603-4609$

Aran D, Toperoff G, Rosenberg M, Hellman A (2011) Replication timingrelated and gene body-specific methylation of active human genes. Hum Mol Genet 20: 670-680

Ball MP, Li JB, Gao Y, Lee JH, LeProust EM, Park IH, Xie B, Daley GQ, Church GM (2009) Targeted and genome-scale strategies reveal gene-body methylation signatures in human cells. Nat Biotechnol 27: $361-368$

Bird AP (1986) CpG-rich islands and the function of DNA methylation. Nature 321(6067): 209-213

Blahnik KR, Dou L, Echipare L, Iyengar S, O'Geen H, Sanchez E, Zhao Y, Marra MA, Hirst M, Costello JF, Korf I, Farnham PJ (2011) Characterization of the contradictory chromatin signatures at the $3^{\prime}$ exons of zinc finger genes. PLoS One 6(2): e17121

Carrozza MJ, Li B, Florens L, Suganuma T, Swanson SK, Lee KK, Shia WJ, Anderson S, Yates J, Washburn MP, Workman JL (2005) Histone H3 methylation by Set2 directs deacetylation of coding regions by Rpd3S to suppress spurious intragenic transcription. Cell 123: 581-592

Cedar H, Bergman Y (2009) Linking DNA methylation and histone modification: patterns and paradigms. Nat Rev Genet 10(5): 295-304

Choi JK (2010) Contrasting chromatin organization of CPG islands and exons in the human genome. Genome Biol 11(7): R70

Choi JK, Bae JB, Lyu J, Kim TY, Kim YJ (2009) Nucleosome deposition and DNA methylation at coding region boundaries. Genome Biol 10(9): R89

Fandy TE, Carraway H, Gore SD (2007) DNA demethylating agents and histone deacetylase inhibitors in hematologic malignancies. Cancer J 13: $40-48$

Feng S, Cokus SJ, Zhang X, Chen PY, Bostick M, Goll MG, Hetzel J, Jain J, Strauss SH, Halpern ME, Ukomadu C, Sadler KC, Pradhan S, Pellegrini M, Jacobsen SE (2010) Conservation and divergence of new insights are being gained rapidly. As more cell types are bisulphite sequenced and published in freely available databases, and as more individuals are analysed, the challenges ahead will be in ensuring the depth of sequence reads and computational handling are optimised for the analysis of such high volumes of data. Only when these challenges are met will verifiable novel insights into the mechanisms of DNA methylation transcriptional control be possible. By studying CGI promoters exclusively, we have only scratched the surface of the epigenetic landscape of normal and cancer cells. Demethylating agents, including 5azacytidine, are already being used in the management of haematological malignancies and myelodysplastic syndrome, and are in clinical trials for multiple solid tumours. The ability to target specifically aberrant regions of methylation in cancer cells holds promise for truly personalised therapies. However, a thorough understanding of the basic mechanisms of DNA methylation in transcriptional control, including the role of IGM, is critical to fully understand the consequences and side effects of such treatments.

\section{ACKNOWLEDGEMENTS}

This work was funded by the Breast Cancer Campaign fellowship to JMF and Cancer Research UK program Grant C536/A6689. JMF was funded by the Breast Cancer Campaign, and NS was funded by a Medical Research Council PhD studentship. We would like to thank Professor Robert Brown for his critical review of this manuscript. methylation patterning in plants and animals. Proc Natl Acad Sci USA 107(19): $8689-8694$

Flanagan JM (2011) DNA methylation profiling to identify known and novel tumour subtypes. In Horizons in Cancer Research, Watanabe HS (ed) Vol. 46, Chapter II. Nova Science Publishers: New York

Flanagan JM, Munoz-Alegre M, Henderson S, Tang T, Sun P, Johnson N, Fletcher O, Dos Santos Silva I, Peto J, Boshoff C, Narod S, Petronis A (2009) Gene-body hypermethylation of ATM in peripheral blood DNA of bilateral breast cancer patients. Hum Mol Genet 18(7) $1332-1342$

Flower K, Hellen E, Newport MJ, Jones S, Sinclair AJ (2010) Evaluation of a prediction protocol to identify potential targets of epigenetic reprogramming by the cancer associated Epstein Barr virus. PLoS One 5(2): e9443

Fu S, Hu W, Iyer R, Kavanagh JJ, Coleman RL, Levenback CF, Sood AK, Wolf JK, Gershenson DM, Markman M, Hennessy BT, Kurzrock R, Bast Jr RC (2011) Phase 1b-2a study to reverse platinum resistance through use of a hypomethylating agent, azacitidine, in patients with platinumresistant or platinum-refractory epithelial ovarian cancer. Cancer 117(8) $1661-1669$

Gal-Yam EN, Egger G, Iniguez L, Holster H, Einarsson S, Zhang X, Lin JC, Liang G, Jones PA, Tanay A (2008) Frequent switching of Polycomb repressive marks and DNA hypermethylation in the PC3 prostate cancer cell line. Proc Natl Acad Sci USA 105(35): 12979-12984

Guenther MG, Levine SS, Boyer LA, Jaenisch R, Young RA (2007) A chromatin landmark and transcription initiation at most promoters in human cells. Cell 130: 77-88

Hahn MA, Hahn T, Lee DH, Esworthy RS, Kim BW, Riggs AD, Chu FF, Pfeifer GP (2008) Methylation of polycomb target genes in intestinal cancer is mediated by inflammation. Cancer Res 68(24): 10280-10289

Hahn MA, Wu X, Li AX, Hahn T, Pfeifer GP (2011) Relationship between gene body DNA methylation and intragenic $\mathrm{H} 3 \mathrm{~K} 9 \mathrm{me} 3$ and $\mathrm{H} 3 \mathrm{~K} 36 \mathrm{me} 3$ chromatin marks. PLoS One 6(4): e18844

Han H, Cortez CC, Yang X, Nichols PW, Jones PA, Liang G (2011) DNA methylation directly silences genes with non-CpG island promoters and establishes a nucleosome occupied promoter. Hum Mol Genet 20(22): $4299-4310$

Hawkins RD, Hon GC, Lee LK, Ngo Q, Lister R, Pelizzola M, Edsall LE, Kuan S, Luu Y, Klugman S, Antosiewicz-Bourget J, Ye Z, Espinoza C, 
Agarwahl S, Shen L, Ruotti V, Wang W, Stewart R, Thomson JA, Ecker JR, Ren B (2010) Distinct epigenomic landscapes of pluripotent and lineage-committed human cells. Cell Stem Cell 6(5): 479-491

Hellman A, Chess A (2007) Gene body-specific methylation on the active X chromosome. Science 315(5815): 1141-1143

Hodges E, Molaro A, Dos Santos CO, Thekkat P, Song Q, Uren PJ, Park J, Butler J, Rafii S, McCombie WR, Smith AD, Hannon GJ (2011) Directional DNA methylation changes and complex intermediate states accompany lineage specificity in the adult hematopoietic compartment. Mol Cell 44: 17-28

Huff JT, Plocik AM, Guthrie C, Yamamoto KR (2010) Reciprocal intronic and exonic histone modification regions in humans. Nat Struct Mol Biol 17: $1495-1499$

Jones PA, Baylin SB (2007) The epigenomics of cancer. Cell 128(4): 683-692 Komashko VM, Acevedo LG, Squazzo SL, Iyengar SS, Rabinovich A, O'Geen H, Green R, Farnham PJ (2008) Using ChIP-chip technology to reveal common principles of transcriptional repression in normal and cancer cells. Genome Res 18(4): $521-532$

Komashko VM, Farnham PJ (2010) 5-azacytidine treatment reorganizes genomic histone modification patterns. Epigenetics 5(3): 229-240

Li Y, Zhu J, Tian G, Li N, Li Q, Ye M, Zheng H, Yu J, Wu H, Sun J, Zhang H, Chen Q, Luo R, Chen M, He Y, Jin X, Zhang Q, Yu C, Zhou G, Huang Y, Cao H, Zhou X, Guo S, Hu X, Li X, Kristiansen K, Bolund L, Xu J, Wang W, Yang H, Wang J, Li R, Beck S, Zhang X (2010) The DNA methylome of human peripheral blood mononuclear cells. PLoS Biol 8(11): e1000533

Lieb JD, Clarke ND (2005) Control of transcription through intragenic patterns of nucleosome composition. Cell 123: 1187-1190

Lorincz M, Dickerson D, Schmitt M, Groudine M (2004) Intragenic DNA methylation alters chromatin structure and elongation efficiency in mammalian cells. Nat Struct Mol Biol 11(11): $1068-1075$

Maunakea AK, Nagarajan RP, Bilenky M, Ballinger TJ, D'Souza C, Fouse SD, Johnson BE, Hong C, Nielsen C, Zhao Y, Turecki G, Delaney A, Varhol R, Thiessen N, Shchors K, Heine VM, Rowitch DH, Xing X, Fiore C, Schillebeeckx M, Jones SJ, Haussler D, Marra MA, Hirst M, Wang T, Costello JF (2010) Conserved role of intragenic DNA methylation in regulating alternative promoters. Nature 466(7303): 253-257

Nanty L, Carbajosa G, Heap GA, Ratnieks F, van Heel DA, Down TA, Rakyan VK (2011) Comparative methylomics reveals gene-body H3K36me3 in Drosophila predicts DNA methylation and CpG landscapes in other invertebrates. Genome Res 21(11): 1841-1850

$\mathrm{Ng} \mathrm{HH}$, Bird A (1999) DNA methylation and chromatin modification. Curr Opin Genet Dev 9: 158-163

Rauch TA, Wu X, Zhong X, Riggs AD, Pfeifer GP (2009) A human B cell methylome at 100-base pair resolution. Proc Natl Acad Sci USA 106: 671-678
Rishi V, Bhattacharya P, Chatterjee R, Rozenberg J, Zhao J, Glass K, Fitzgerald P, Vinson C (2010) CpG methylation of half-CRE sequences creates $\mathrm{C} / \mathrm{EBPalpha}$ binding sites that activate some tissue-specific genes. Proc Natl Acad Sci USA 107(47): 20311-20316

Schulz WA, Goering W (2011) Eagles report: developing cancer biomarkers from genome-wide DNA methylation analyses. World J Clin Oncol 2(1): $1-7$

Segal E, Widom J (2009) What controls nucleosome positions? Trends Genet 25(8): 335-343

Shann YJ, Cheng C, Chiao CH, Chen DT, Li PH, Hsu MT (2008) Genomewide mapping and characterization of hypomethylated sites in human tissues and breast cancer cell lines. Genome Res 18: 791-801

Smith JF, Mahmood S, Song F, Morrow A, Smiraglia D, Zhang X, Rajput A, Higgins MJ, Krumm A, Petrelli NJ, Costello JF, Nagase H, Plass C, Held WA (2007) Identification of DNA methylation in $3^{\prime}$ genomic regions that are associated with upregulation of gene expression in colorectal cancer. Epigenetics 2(3): $161-172$

Suzuki MM, Bird A (2008) DNA methylation landscapes: provocative insights from epigenomics. Nat Rev Genet 9: 465-476

Takai D, Jones PA (2002) Comprehensive analysis of CpG islands in human chromosomes 21 and 22. Proc Natl Acad Sci USA 99: 3740-3745

Tufarelli C, Stanley JA, Garrick D, Sharpe JA, Ayyub H, Wood WG, Higgs DR (2003) Transcription of antisense RNA leading to gene silencing and methylation as a novel cause of human genetic disease. Nat Genet 34: $157-165$

Weber M, Davies JJ, Wittig D, Oakeley EJ, Haase M, Lam WL, Schubeler D (2005) Chromosome-wide and promoter-specific analyses identify sites of differential DNA methylation in normal and transformed human cells. Nat Genet 37: $853-862$

Wild L, Flanagan JM (2010) Genome-wide hypomethylation in cancer may be a passive consequence of transformation. Biochim Biophys Acta 1806(1): $50-57$

Yoder JA, Walsh CP, Bestor TH (1997) Cytosine methylation and the ecology of intragenomic parasites. Trends Genet 13: 335-340

Zemach A, McDaniel IE, Silva P, Zilberman D (2010) Genome-wide evolutionary analysis of eukaryotic DNA methylation. Science 328(5980): 916-919

Zhang X, Yazaki J, Sundaresan A, Cokus S, Chan SW, Chen H, Henderson IR, Shinn P, Pellegrini M, Jacobsen SE, Ecker JR (2006) Genome-wide high-resolution mapping and functional analysis of DNA methylation in arabidopsis. Cell 126: 1189-1201

Zilberman D, Gehring M, Tran RK, Ballinger T, Henikoff S (2007) Genomewide analysis of Arabidopsis thaliana DNA methylation uncovers an interdependence between methylation and transcription. Nature genetics 39(1): $61-69$ 